\title{
Benzimidazol halkasının antimikrobiyal aktivitesine etki eden yapısal faktörlerin disk difüzyon ve mikrodilüsyon metodu ile ayrıntılı incelenmesi
}

\author{
Fadime ÖZDEMİ-KOCAK ${ }^{1,2 *}$, Bilge EREN $^{3}$ \\ ${ }^{I}$ Sağllk Yüksekokulu Hemşirelik Bölümü, Bilecik Şeyh Edebali Üniversitesi, Bilecik \\ ${ }^{2}$ Biyoteknoloji Uygulama ve Araştırma Merkezi, Bilecik Şeyh Edebali Üniversitesi, Bilecik \\ ${ }^{3}$ Fen Edebiyat Fakültesi Kimya Bölümü, Bilecik Şeyh Edebali Üniversitesi, Bilecik
}

Geliş Tarihi (Recived Date): 26.11.2017

Kabul Tarihi (Accepted Date): 06.11.2018

\section{Özet}

Birçok antimikrobik maddeye karşı direnç geliştirmiş mikroorganizmaların oluşturduğu toplumsal ve hastane kaynaklı enfeksiyonlar büyük bir sorun oluşturmaktadır ve bu enfeksiyonların tedavisinde yeni ajanların kullanımı ile sağaltımın etkili olması sağlanabilmektedir. Bu çalışmada yapısal farklılıklar içeren bazı benzimidazol türevlerinin antimikrobiyal etkileri mikrodilüsyon ve disk diffüsyon tekniklerini kullanarak incelenmiştir. Çalışılan bileşikler içerdikleri benzimidazol birimi sayısı, benzimidazol halkasının 1 ve 5 konumunda farklı sübstitüsyonu, 2-fenilbenzimidazol yapısının p- konumunda farklı sübstitüsyonu ve aromatik birimler içerip içermemeleri gibi yönlerden farklllıklar içermektedir. Bu yolla amaca uygun yeni benzimidazollerin sentezi için literatüre yapı-aktivite ilişkilerine dair önemli bilgilerin kazandırılması hedeflenmiştir. İncelenmek üzere, klinikte önem taşıyan ve direnç oluşumu açısından da önemli olan Gram + ve Gram -bakterileri içeren klinik tip türleri seçilmiştir. Benzimidazol türevi maddelerin etkileri standart antimikrobik ajanlarla kıyaslanmıştır. Benzimidazol halkasının sayısına bağlı olarak antimikrobiyal etkinin arttı̆̆l, benzimidazole 2- konumunda bağll tiyofen ve piridin gibi hetero halkall grupların aktiviteyi arttırdı ̆̆l, 5-Cl sübstitüsyonunun benzimidazole tüm bakteri türlerine karşı etkili olma özelliği kazandırdı ̆̆ belirlenmiştir. Ayrıca, 2-fenil benzimidazolün pkonumunda elektron çekici $\mathrm{Cl}$ ve $\mathrm{NO}_{2}$, içeren türevlerin elektron verici $\mathrm{OCH}_{3}$ ve $\mathrm{CH}_{3}$ içeren türevlere göre bakteri türlerine karşı daha etkin olduğu tespit edilmiştir.

Anahtar kelime: Benzimidazol, mikrodilüsyon, disk diffüsyon.

\footnotetext{
* Fadime ÖZDEMIR KOÇAK, fadime.ozdemirkocak@bilecik.edu.tr, http://orcid.org/0000-0001-6608-0398 Bilge EREN, bilge.eren@ bilecik.edu.tr, http://orcid.org/0000-0001-9775-9360
} 


\title{
Detailed examination of structural factors effecting antimicrobial activity of benzimidazole ring by disk diffusion and microdilution method
}

\begin{abstract}
Socio-and hospital-acquired infections caused by microorganisms that have developed resistance to many antimicrobial agents constitute a major problem, and the use of new agents in the treatment of these infections can make treatment effective. In this study, antimicrobial effects of different benzimidazole derivatives were investigated using microdilution and disc diffusion techniques. The compounds studied include differences in the number of benzimidazole units they contain, the different substitutions of the benzimidazole ring in positions 1 and 5, the different substitution of the 2-phenyl benzimidazole structure in the p-position, and the presence or absence of aromatic units. In this way, it is aimed to gain important knowledge to the literature about structure-activity relations for the synthesis of novel benzimidoles which are suitable for the purpose. To examine, clinical types including Gram +and Gram -bacteria, which are clinically important and important for resistance formation, have been selected. The activity of benzimidazole derivatives was compared with standard antimicrobial agents. Results indicated that antimicrobial activity increases proportionally with the number of benzimidazole rings, heterocyclic groups such as thiophene and pyridine connected to benzimidazole at position 2-increases the activity, 5-Cl substituion get benzimidazole to be active against all bacterial species. Also, it was determined that the derivates having electron withdrawing $\mathrm{Cl}$ and NO2 sübstitüents at the p-position of 2-phenyl benzimidazole are more effective than the derivates having electron donating $\mathrm{OCH}_{3}$ ve $\mathrm{CH}_{3}$ sübstitüents against bacterial strains.
\end{abstract}

Keywords: Benzimidazole, microdilution, disc diffusion.

\section{Giriș}

Nozokomiyal ve toplumsal kökenli enfeksiyon oluşumlarından farklı bakteri cins üyesi insan patojenleri bulunmaktadır. Gram pozitif bakterilerden Staphylococcus ve Bacillus, Gram negatif bakterilerden Escherichia ve Pseudomonas, kan dolaşımı ve yumuşak doku enfeksiyonları, endokardit, pnömoni, bakteriyemi, endokardit, yara veya cerrahi alan enfeksiyonları ve menenjit gibi birçok farklı enfeksiyona neden olabilmektedir. Özellikle $S$. aureus ve $P$. aeruginosa, bir haftadan daha uzun süre hastanede yatan hastalardan izole edilen en yaygın patojendir. Bu patojenler yaygın hastane (nozokomiyal) enfeksiyonlarının da nedeni olduğu bilinmektedir [1].

Bakteri ve mantarların yol açtığı bulaşıcı hastalıklarda hala direncin oluşumu önemli bir sağlık problemidir. Dirençli bakterilerin gelişimi, mevcut antimikrobiyal ve antifungal ilaçların artan ve yanlış kullanımından kaynaklanmaktadır. Son yıllarda, Staphylococcus aureus (MRSA), Pseudomonas aeruginosa, Streptococcus pneumoniae, Enterococcus faecalis, Acinetobacter baumannii ve Morganella morganii gibi metisiline dirençli mikroorganizmalar maliyetli tıbbi tedavi açısından oldukça öneme sahiptirler [2]. 
Son dönemde, bahsedilen enfeksiyon hastalıklarına karşı yeni antimikrobiyal ajanların keşfi ciddi önem taşımaktadır. Benzimidazol türevleri ise, antitümör [3-4], antidiabetik [5-6], antienflamatuar [6], antiviral [6-7], antikoagulant [6], antifungal [7-8] ve antimikrobiyal [6-9] ajanlar gibi farmasötik ve terapötik uygulamalarda kullanımlarından dolayı büyük ilgi görmektedir. Bu çalışmanın temel amacı, önemli bir farmasötik madde sınıfı olan benzimidazollerin yapı-aktivite ilişkilerine yönelik detaylı veriler elde ederek yeni farmasötik ajanların geliştirilmesine katkı sağlamaktır. Disk diffüsyon ve mikrodilüsyon yöntemlerinin aynı zamanda karşılaştırılması, standart antibiyotik duyarlılı testlerinin yorumlanmasına katkı sağlayarak direnç mekanizmalarının daha iyi anlaşılmasını ve dolayısıyla akılcı tedavinin seçilmesine de katkı sağlayabilir. Benzimidazol türevlerinin mikrodalga yardımıyla sentezi Eren vd. tarafından daha önce yayınlanmıştır [10-11]. Bu çalışmada elde edilen benzimidazol türevlerinden yapısal farklılıklar içeren on beş bileşiğin antibakteriyel aktiviteleri broth mikrodilüsyon (MIC) ve disk difüzyon yöntemleri ile incelenmiştir. İncelenen türevler, içerdikleri benzimidazol birimi sayısı, benzimidazol halkasının 1 ve 5 konumunda farklı sübstitüsyonu, 2-fenil benzimidazol yapısının para konumunda farklı sübstitüsyonu ve aromatik birimler içerip içermemeleri gibi yönlerden farkl1lıklar göstermektedir. Dolayısıyla, sonuçların değerlendirilmesi ile yapı-aktivite ilişkileri hakkında önemli bilgiler elde edilmiştir.

\section{Deneysel çalışmalar}

\subsection{Benzimidazol türevlerinin sentezi}

Benzimidazol türevleri, Eren vd. tarafından tanımladığg gibi, mikrodalgada $180 \mathrm{~W}$ 'ta ofenilen diaminlerin karşılık gelen aldehitlerin ve dialdehitlerin bisülfit katılma ürünleri ile muamele edilmesi yöntemi ile sentezlenmiştir [10-11]. Özet olarak; Bisülfit katılma ürünleri, eşdeğer miktardaki soğuk aldehit/etanol ve sodyum hidrojen sülfit/su karışımlarının muamelesi ile elde edilmiştir. Ardından, deney balonu içerisinde substitue o-fenilendiamin (benzimidazoller için $2 \mathrm{mmol}$, bisbenzimidazoller için 4 mmol) ve karşıllk gelen aldehit bisülfit katılma ürünü (2.1 mmol) birkaç damla DMF ile 1slatılmiş ve belli sürelerde (2-25 dakika) mikrodalga 1şılnlarına maruz bırakılmıştır (180 W). Ürünler, reaksiyon karışımının buzlu suda çöktürülmesi ile elde edilmiştir. Elde edilen maddeler etanol/su karışımında kristallendirilerek saflaştırılmış olup reaksiyonların verimi genel olarak \% 64-95 aralığındadır. Bileşiklerin bazılarına ait fiziksel ve spektral veriler daha önce verildiğinden burada gerek duyulmamıştır [10-11]. Diğer bileşiklerin bazı fiziksel ve spektral verileri aşağıda özetlenmiştir:

5 no'lu madde. m.p. $313-316^{\circ} \mathrm{C}$. IR $\left(\mathrm{v}, \mathrm{cm}^{-1}\right)$ : 3033, 1610, 1520, 1434, 1320, 730; ${ }^{1} \mathrm{H}$ NMR (400 MHz, DMSO- $\left.d_{6}\right): \delta 7.00-7.13(\mathrm{~m}, 2 \mathrm{H}), 7.58(\mathrm{dd}, 2 \mathrm{H}), 7.93(\mathrm{~d}, 2 \mathrm{H}), 8.21(\mathrm{~d}$, $2 \mathrm{H}), 12.93$ (bs, 1H, NH).

7 no'lu madde. m.p. $223^{\circ} \mathrm{C}$. IR (v, $\left.\mathrm{cm}^{-1}\right)$ : 3065-2537, 3065, 1625, 1574-1446, 1319, 1242, 706, 604; ${ }^{1} \mathrm{H}$ NMR (400 MHz, DMSO- $\left.d_{6}\right): \delta 7.19(\mathrm{~s}, 1 \mathrm{H}), 7.22(\mathrm{dd}, 1 \mathrm{H}), 7.54(\mathrm{~d}$, $1 \mathrm{H}), 7.60(\mathrm{~s}, 1 \mathrm{H}), 7.74(\mathrm{~d}, 1 \mathrm{H}), 7.84(\mathrm{~d}, 1 \mathrm{H}), 13.17(\mathrm{bs}, 1 \mathrm{H}, \mathrm{NH})$.

8 no'lu madde. m.p. $248-249^{\circ} \mathrm{C}$. IR $\left(\mathrm{v}, \mathrm{cm}^{-1}\right)$ : 3018-2528, 3018, 2935, 2861, 1651, 1557, 1319, 1242, 604; ${ }^{1} \mathrm{H}$ NMR (400 MHz, DMSO- $\left.d_{6}\right): \delta 2.40\left(\mathrm{~s}, 3 \mathrm{H}, \mathrm{CH}_{3}\right), 7.00(\mathrm{~d}$, $1 \mathrm{H}), 7.20(\mathrm{t}, 1 \mathrm{H}), 7.32(\mathrm{~s}, 1 \mathrm{H}), 7.42(\mathrm{~d}, 1 \mathrm{H}), 7.68(\mathrm{~d}, 1 \mathrm{H}), 7.80(\mathrm{~d}, 1 \mathrm{H}), 12.79(\mathrm{bs}, 1 \mathrm{H}$, $\mathrm{NH})$.

9 no'lu madde. m.p. $239-241^{\circ} \mathrm{C}$. IR (v, $\left.\mathrm{cm}^{-1}\right)$ : 3371, 3200-2666, 3027, 1617, 1574, 1455, 1271, 1209; ${ }^{1} \mathrm{H}$ NMR (400 MHz, DMSO- $\left.d_{6}\right): \delta 5.09$ (s, $\left.1 \mathrm{H}, \mathrm{OH}\right), 7.25(\mathrm{dd}, 2 \mathrm{H})$, 
$7.32(\mathrm{~d}, 1 \mathrm{H}), 7.37(\mathrm{t}, 1 \mathrm{H}), 7.39(\mathrm{~d}, 1 \mathrm{H}), 7.51(\mathrm{t}, 1 \mathrm{H}), 7.66(\mathrm{dd}, 2 \mathrm{H}), 7.95(\mathrm{~d}, 1 \mathrm{H}), 8.20$ (d, 1H), 12.25 (bs, 1H, NH).

10 no'lu madde. m.p. $233-235^{\circ} \mathrm{C}$. IR $\left(v, \mathrm{~cm}^{-1}\right)$ : 3380, 3200-2666, 3071, 1618, 1571, 1463, 1276, 1209, 739; ${ }^{1} \mathrm{H}$ NMR (400 MHz, DMSO-d $): \delta 7.27(\mathrm{dd}, 1 \mathrm{H}), 7.34(\mathrm{~d}, 1 \mathrm{H})$, $7.37(\mathrm{~d}, 1 \mathrm{H}), 7.49(\mathrm{t}, 1 \mathrm{H}), 7.66(\mathrm{~d}, 1 \mathrm{H}), 7.71(\mathrm{~s}, 1 \mathrm{H}), 7.88(\mathrm{~d}, 1 \mathrm{H}), 7.95(\mathrm{~d}, 1 \mathrm{H}), 8.22(\mathrm{~d}$, $1 \mathrm{H}), 12.05$ (bs, 2H, NH, OH) .

11 no'lu madde. m.p. $218-220^{\circ} \mathrm{C}$. IR $\left(\mathrm{v}, \mathrm{cm}^{-1}\right): 3295,3145-2666,3047,2915,2853$, $1620,1601,1475,1278,1212 ;{ }^{1} \mathrm{H}$ NMR (400 MHz, DMSO- $\left.d_{6}\right): \delta 2.45\left(\mathrm{~s}, 3 \mathrm{H}, \mathrm{CH}_{3}\right)$, $7.08(\mathrm{~d}, 1 \mathrm{H}), 7.31(\mathrm{~d}, 1 \mathrm{H}), 7.37(\mathrm{t}, 1 \mathrm{H}), 7.44(\mathrm{~s}, 1 \mathrm{H}), 7.51(\mathrm{~d}, 1 \mathrm{H}), 7.54(\mathrm{~d}, 1 \mathrm{H}), 7.89(\mathrm{~d}$, $1 \mathrm{H}), 7.94(\mathrm{~d}, 1 \mathrm{H}), 8.22(\mathrm{~d}, 1 \mathrm{H}), 12.25(\mathrm{bs}, 2 \mathrm{H}, \mathrm{NH}, \mathrm{OH})$.

12 no'lu madde. m.p. $280-283^{\circ} \mathrm{C}$. IR $\left(\mathrm{v}, \mathrm{cm}^{-1}\right)$ : 3048, 2944, 2868, 1591, 1530, 1442 , 1330, 1277; ${ }^{1} \mathrm{H}$ NMR (400 MHz, DMSO- $\left.d_{6}\right): \delta 3.54\left(\mathrm{~s}, 3 \mathrm{H}, \mathrm{NCH}_{3}\right), 7.36-7.24(\mathrm{~m}, 6 \mathrm{H})$, $7.61(\mathrm{~d}, 1 \mathrm{H}), 7.72(\mathrm{~d}, 1 \mathrm{H}), 7.88(\mathrm{~d}, 1 \mathrm{H}), 7.98(\mathrm{~d}, 1 \mathrm{H})$.

13 no'lu madde. m.p. $219-222^{\circ} \mathrm{C}$. IR $\left(\mathrm{v}, \mathrm{cm}^{-1}\right)$ : 3320, 3060, 1589, 1505, 1489, 1439, 1298, 1277, 994; ${ }^{1} \mathrm{H}$ NMR (400 MHz, DMSO-d6): $87.22-7.25$ (m, 2H), 7.53 (dd, 1H), $7.68(\mathrm{~d}, 2 \mathrm{H}), 8.11(\mathrm{dd}, 1 \mathrm{H}), 8.43(\mathrm{~d}, 1 \mathrm{H}), 8.83(\mathrm{~d}, 1 \mathrm{H}), 13.11(\mathrm{bs}, 1 \mathrm{H})$.

\subsection{Mikrobiyal suşlar}

Gram-pozitif bakterilerden Bacillus subtilis NRLL-B 209, Staphylococcus aureus ATCC 25923, Gram negatif bakterilerden Escherichia coli ATCC 25922, Pseudomonas aeruginosa ATCC 27853antimikrobiyal aktivite çalışmalarında kullanılmıştır. Tüm test tip türleri, NRLL-B ve ATCC kültür koleksiyonlarından elde edilmiștir.

\subsection{Antibakteriyel aktivite taramast}

Antibakteriyal çalışmalar, Ulusal Klinik Laboratuar Standartları Komitesi'nde [12] açıklandığı üzere broth mikrodilüsyon yöntemi ve agar disk difüzyon yöntemine göre gerçekleştirilmiştir. Test edilen suşlara karşı benzimidazol türevlerinin (1-15) minimum inhibisyon konsantrasyonları (MIC'ler), 96 çok oyuklu mikro plakalarda broth mikrodilüsyon metodu kullanılarak belirlenmiştir [12-13]. Test suşları Mueller Hinton brothda $37^{\circ}$ C'de 24-48 saat inkübe edilmiş ve hazırlanan süspansiyonların bulanıklığ 1 0.5 McFarland'a ayarlanmıştır. Benzimidazole bileşikleri Dimetil sülfoksid içinde çözülmüş ve aynı çözücü kullanılarak seyreltilmiştir. Sarker ve diğerlerinin tanımladığı yöntem kullanılarak, seri olarak iki kez seyreltilen numunelerin 96 kuyucuklu mikrotitrasyon plakası hazırlanmıştır [14]. Stok konsantrasyonu $40 \mathrm{mg} / \mathrm{ml}$ olarak ayarlanmıştır. MIC değeri görünür büyümeyi engelleyen örneklerin en düşük konsantrasyonu olarak saptanmıştır. Minimum bakterisid konsantrasyonunu (MBC) belirlemek için, bakteri büyümesinin olmadığı herbir kuyucuktan $10 \mu 1$ örnek alınmış ve $37^{\circ} \mathrm{C}^{\prime}$ de 24 saat süreyle Sensitest agarda inoküle edilmiştir. İnkübasyondan sonra, MBC değeri petri kaplarında büyüme göstermeyen en düşük konsantrasyon olarak tespit edilmiştir. MBC değeri, test edilen numunenin bakteri hücrelerinin\% 99.9'unun öldürüldüğü en düşük konsantrasyon olarak değerlendirilmektedir. Her bir test, olası test hatalarını minimuma indirgemek amacıyla üçer defa yapılmıştır.

B. subtilis, E. coli, S. aureus ve $P$. aeruginosa test suşlarına karşı sentezlenen bileşiklerin antimikrobiyal potansiyeli gibi önemli bilgiler elde etmek için agar disk difüzyon yöntemi uygulanmıştır. Dimetilsülfoksit (DMSO, Merck) içinde çözdürülen bileşiklerin antimikrobik etkisi üç farklı konsantrasyonda (250, 500 ve $1000 \mathrm{ug} / \mathrm{ml}$ ) test edilmiştir. Benzimidazole türevlerinin antimikrobiyal aktivitesini belirlemek için Sensitest agar (Oxoid) kullanılmıştır. İnokülasyon sonrası bakteriler $37^{\circ} \mathrm{C}$ de 24 saat boyunca bir döner çalkalayıcıda inkübe edilmiştir. Süspansiyonların yaklaşık 
konsantrasyon değeri $10^{6}-10^{8} \mathrm{CFU} / \mathrm{ml}$ (0.5 McFarland standard, Vitek kolorimetresi) olarak Ulusal Klinik Laboratuvar Standartları Komitesi [12] tavsiyelerine uygun olarak düzenlenmiştir. 0.5 McFarland olarak ayarlanan test suşları, katı sensitest agar yüzeyine

steril eküvyon çubuk ile yayılmıştır. Ekim sonrasında; 250, 500 ve $1000 \mathrm{mg}$ son konsantrasyona sahip emici kağıt diskleri agar yüzeyine (bileşikler ve antibiyotikler için $6 \mathrm{~mm}$ ) yerleştirilmiştir. Kontrol amaçlı kullanılan antimikrobiyal ajanların her biri ayrı bir plakada test edilmiştir. Deney çözeltilerinin hazırlanmasında kullanılan DMSO, kontrol amacıyla kullanılmıştır. Ekim yapılan ve disklerin yerleştirildiği petriler $37^{\circ} \mathrm{C}$ 'de, inkübe edilmiştir. Diskin etrafındaki inhibisyon zonu, genellikle büyümenin bir kenardan diğer kenara inhibe olduğu ve bölgenin en keskin kenarına tekabül eden ve kumpast ile milimetre $(\mathrm{mm})$ cinsinden ölçülebilen çap1 [15] olarak alınmıştır. Benzimidazol türevi bileşiklerin her bir test suşuna karşı oluşturduğu antimikrobiyal etki, standart olarak kullanılan antimikrobik ajanın oluşturduğu inhibisyon zonları ile kıyaslanarak değerlendirilmiştir. Tüm testler üçer kez tekrar edilmiş ve ortalama değerler sonuç değeri olarak belirlenmiştir.

\section{Bulgular}

$\mathrm{Bu}$ çalışmada, farklı yapıdaki benzimidazol türevi bileşiklerin (1-15) in vitro antimikrobiyal aktivite özellikleri, broth mikrodilüsyon ve disk difüzyon yöntemleriyle [12] klinik tip suşları üzerinde test edilmiştir. Broth mikrodilüsyon metodu ile MIC değeri belirlenen benzimidazol türevlerinin $\mathrm{MBC}$ değeri sensitest agar yüzeyine inoküle edilerek tespit edilmiştir. Elde edilen sonuçlar Tablo 1'de verilmiştir.

MIC ile antimikrobiyal maddenin gözle görünür üremeyi engelleyen en düşük konsantrasyonu belirlenir. MIC değerinin belirlenmesi, antimikrobiyal maddenin serum düzeyinin belirlenmesini de sağlamaktadır. Bir antimikrobiyal maddenin sağaltımının başarısı için MIC değerinin serum düzeyinden 4-16 kez düşük olması istenmektedir [16].

Para konumunda $\mathrm{H}, \mathrm{CH}_{3}, \mathrm{OCH}_{3}, \mathrm{CI} \mathrm{NO}_{2}$, grupları içeren 2-fenil-benzimidazol yapılarını (1-5) antimikrobiyal etkinliği kendi aralarında değerlendirildiğinde, MIC değerleri 3.91-125 $\mu \mathrm{g} / \mathrm{ml}$ aralığında elde edilmiştir. B. subtilis ve $P$. aeruginosa karşı en etkin maddenin 5 nolu madde olduğunu görmekteyiz (sırasıyla 3.91, 7.81 $\mu \mathrm{g} / \mathrm{ml}$ ). Bu maddeyi diğerlerinden farklı kılan elektron çekici $\mathrm{NO}_{2}$ grubu bulundurmasıdır. $\mathrm{Cl}$ grubu içeren 4 nolu madde de nispeten daha az bir antimikrobiyal etkinlik gözlenmesi guptaki elektron çekicilik arttıkça antimikrobiyal etkinliğin arttığını gösterir. $\mathrm{OCH}_{3}$ grubu içeren 3 nolu madde $7.81 \mu \mathrm{g} / \mathrm{ml}$ ile Gram + B. subtilis'e benzer şekilde aktiftir. $\mathrm{CH}_{3}$ grubu içeren 2 nolu madde de ise etkinlik Gram + ve Gram - bakterilerde nispeten daha düşüktür $(125 \mu \mathrm{g} / \mathrm{ml}) . \mathrm{CH}_{3}$ ve $\mathrm{OCH}_{3}$ gruplarının her ikisi de elektron verici olmasına karşın elektronegatif bir atom içeren $\mathrm{OCH}_{3}$ grubunda etkinliğin fazla olması antimikrobiyal aktivitenin grupta bulunan elektronegatif atomla bağlantılı olduğunun göstergesidir. 
Tablo 1. Benzimidazol türevlerinin (1-15) yapıları ve in vitro antimikrobiyal aktivitileri $\mathrm{MC}(\mu \mathrm{g} / \mathrm{ml})$

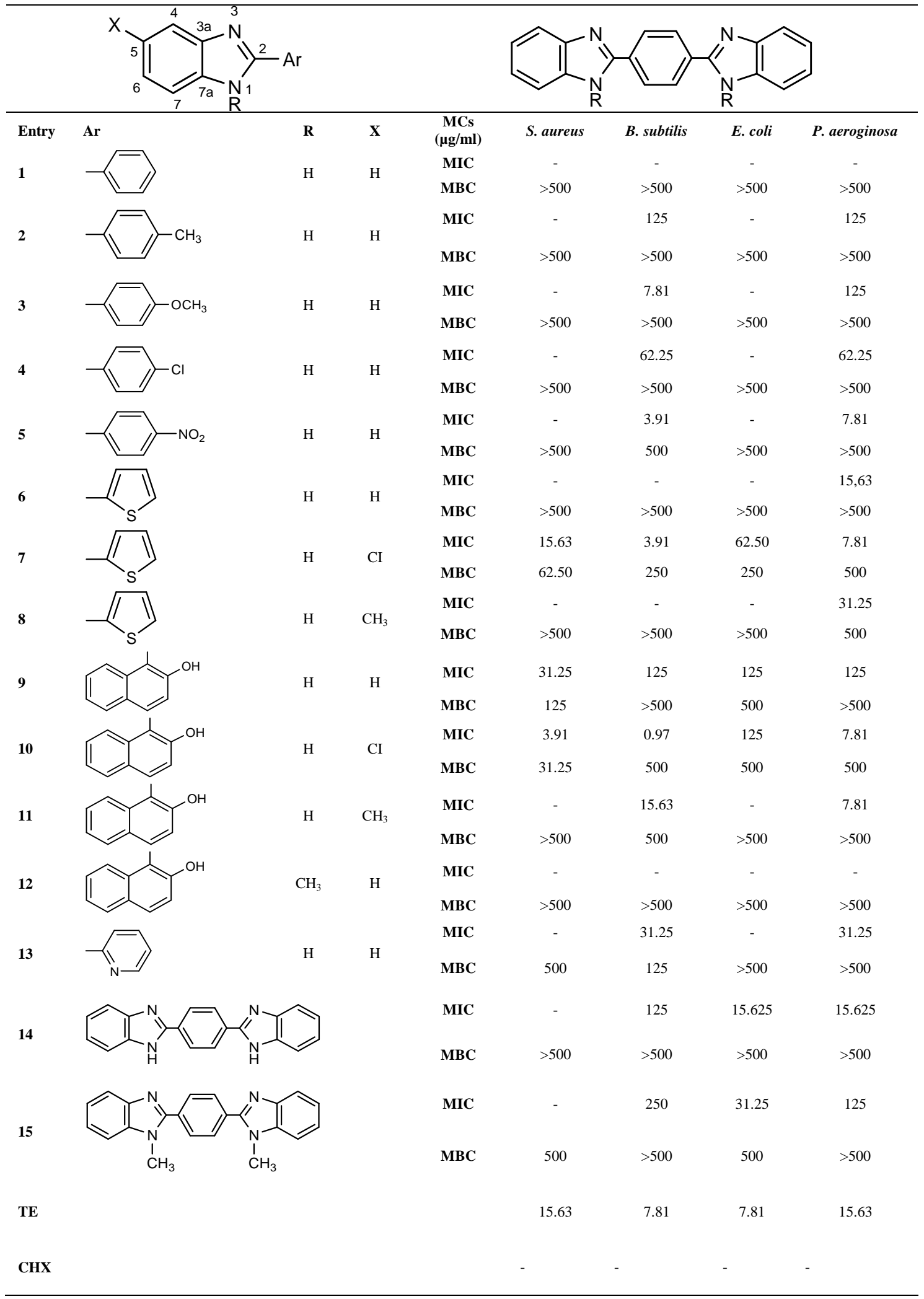

-; test edilemedi

Benzimidazol 2-konumunda tiyofen ve piridin gibi hetero halkalı gruplar içeren türevlerin $(6,13)$ 2-konumunda fenil içeren 1 yapısına kıyasla belirgin şekilde yüksek 
aktiviteye sahip oldukları ortadadır. Piridin halkası içeren 13 nolu maddenin 31.25 $\mu \mathrm{g} / \mathrm{ml}$ MIC değerleri ile $B$. subtilis ve $P$. aeruginosa karşı daha etkin olduğu görülmüştür. 13 no'lu maddenin disk difüzyon deneyi sonucunda $500 \mu \mathrm{g} / \mathrm{ml}$ konsantrasyonda belirgin antimikrobiyal aktiviteye sahip olduğu belirlenmiştir (8-13.5 $\mathrm{mm})$.

Konsantrasyon artışı ile antimikrobiyal etkinliğin artmadığı görülmüştür. $P$. aeruginosa'a karşı en etkin maddenin $15.63 \mu \mathrm{g} / \mathrm{ml}$ ile 6 nolu madde olduğu tespit edilmiştir.

Benzimidazol halkasının 5-konumundaki sübstitüsyonun aktiviteye etkisini; 5-sübstitüe2-(2-hidroksi-1-naftil)benzimidazol türevi bileşiklerini $(9,10,11)$ kendi aralarında kıyaslayarak görmemiz mümkündür. Bunlar arasında $\mathrm{Cl}$ içeren $\mathbf{1 0}$ nolu maddenin 0.97$125 \mu \mathrm{g} / \mathrm{ml}$ arasında etki göstererek tüm test suşlarına karşı antimikrobiyal aktiviteye sahip olduğu belirlenmiştir. $\mathrm{CH}_{3}$ içeren 11 nolu maddenin $P$. aeruginosa ve $B$. subtilis'e karş1 7.81 ve $15.63 \mu \mathrm{g} / \mathrm{ml}$ MIC değerine sahip olduğu görülmüştür. Ayrıca 2hidroksi-1 naftil grubu fenil grubuna kıyasla büyük hacimli bir gruptur. 1 ve 9 nolu maddelerin etkinliğini kıyaslayarak benzimidazol yapısına 2- konumunda bağlı grupların hacminin aktiviteye etkisi tartışılabilir. 9 no'lu madde 1 maddesine kıyasla tüm türlere karşı belirgin bir aktiflik göstermektedir. Buna göre hacimli grupların aktiviteyi artırdığı düşünülebilir, fakat bu artışa naftalin halkasındaki hidroksi grubu da sebep olmuş olabilir.

$6,7,8$ no'lu bileşikler de yine birbirlerinden sadece 5 konumlarındaki sübstitüentlerinin farklı oluşu ile ayrılırlar. Bu bileşikler arasında da $\mathrm{Cl}$ içeren 7 no'lu bileşiğin tüm test suşlarına karşı çok etkili olduğu görülmüştür $(3.91-62.50 \mu \mathrm{g} / \mathrm{ml})$. Aynı zamanda disk difüzyon metodunda da bu maddenin $1000 \mu \mathrm{g} / \mathrm{ml}$ değerinin tüm mikroorganizmalara karşı standart antimikrobik ajanlarla kıyaslandığında daha yüksek inhibüsyon zonları (14-21 mm) oluşturduğu belirlenmiştir.

Benzimidazol ve bisbenzimidazol $(1,14)$ yapılarının antimikrobiyal etkinliği kıyaslandığında bisbenzimidazol yapısının daha yüksek aktivite gösterdiği belirlenmiştir. $\mathrm{Bu}$ durumun antimikrobiyal aktiviteden sorumlu benzimidazol halkasının bu yapılarda iki adet bulunmasından kaynaklandığı düşünülmektedir. Bisbenzimidazol yapısının özellikle Gram - bakterilere yüksek etki gösterdiği görülmektedir $(15.625 \mu \mathrm{g} / \mathrm{ml})$. Maddenin bu etkinliğini disk diffüsyon yönteminden elde edilen sonuçlar da desteklemiştir (8-10 mm).

Benzimidazol halkasının 1-konumunda alkil grupları ile sübstitüe edilmesinin antimikrobiyal aktiviteye etkisini araştırmak amacıyla 9/12 ve 14/15 maddeleri kendi arasında kıyaslamak gerekir. Her iki grup bileşiklerde de 1-konumunda $\mathrm{H}$ yerine metil sübstitüsyonunun aktiviteyi belirgin şekilde azalttığı açıkça görülmektedir. 1-H yapısındaki 9 nolu maddenin test suşlarına karşı antimikrobiyal aktivitesi 31.25-125 $\mu \mathrm{g} / \mathrm{ml}$ belirlenirken 1- $\mathrm{CH}_{3}$ yapısındaki 12 no'lu maddenin bakteri türlerine karşı herhangi bir aktiviteye sahip olmadığı tespit edilmiştir. Benzer şekilde bisbenzimidazol türevlerinde de $1\left(1^{\prime}\right)$-H yapılı 14 no'lu madde $15.65 \mu \mathrm{g} / \mathrm{ml}$ ile belirgin olarak Gram bakterilere karşı etkinlik gösterirken $1\left(1^{\prime}\right)-\mathrm{CH}_{3}$ yapılı 15 no'lu madde aynı bakteri türlerine daha az etkindir $(31.25-125 \mu \mathrm{g} / \mathrm{ml})$. Ayrıca test edilen diğer maddeler ile kıyaslandığında 14 ve 15 nolu maddeler 2 adet benzimidazol halkası içerir ve hacimsel olarak daha büyüktür. Bu iki faktör Gram - bakterilere karşı etkinliği arttırmış görünmektedir. $\mathrm{Bu}$ durumun hücre duvarlarındaki yapısal farklılıktan kaynaklanması 
muhtemeldir. Çünkü bu iki madde haricinde diğer maddelerde Gram - ve Gram + bakterilere karşı etkinlik bir arada bulunmaktadır.

Disk diffüsyon metodu ile benzimidazol türevi maddelerin antimikrobiyal etkileri; Gram + ve Gram - bakterilerden oluşan farklı klinik test suşlarına karşı belirlenmiştir. MIC ve MBC değerleri de göz önüne alınarak 250, 500 ve $1000 \mu \mathrm{g} / \mathrm{ml}$ konsantrasyona sahip diskler hazırlanmıştır. Tüm test mikroorganizmaları için Amikasin (Oxoid), Ampisilin (Oxoid), Karbenisilin (Oxoid), Oflaksasin (Oxoid) ve Tetrasiklin (Oxoid) antibiyotik diskleri pozitif kontrol olarak ve DMSO çözücüsü ise negatif kontrol olarak kullanılmıştır. Disk difüzyon çalışmaların sonuçları Tablo 2 'de verilmektedir.

Test edilen klinik tip suşların ideal gelişimi, sensitest agarda 24 saat inkübasyon ile sağlanmıştır. $0.5 \mathrm{McFarland} \mathrm{standardına}\left(10^{6}-10^{8} \mathrm{CFU} / \mathrm{ml}\right)$ ayarlanan inokülumlar üzerine yerleştirilen benzimidazol türevi maddelerin inhibisyon zonları, 24 saat inkübasyondan sonra tespit edilmiştir. Bu bulgular, NCCLS'nin önerisi [13] ile de uyumludur. 7 ve 13 nolu maddenin tüm test suşlarına karşı etkin olduğu belirlenmiştir (Tablo 2). Ayrica 13 nolu maddenin etkin konsantrasyonu ise $500 \mu \mathrm{g} / \mathrm{ml}$ olarak belirlenmiştir. 7 nolu madde ise $E$. coli hariç tüm test suşlarına karşı yüksek bir antimikrobiyal aktivite gösterdiği ve en yüksek etkiyi $1000 \mu \mathrm{g} / \mathrm{ml}$ konsantrasyonunda gösterdiği tespit edilmiştir $(9-21 \mathrm{~mm}) .15$ no'lu maddenin tüm klinik suşlara düşük oranlarda da olsa antimikrobiyal bir etkinlik gösterdiği görülmüştür (7.5-12 mm). Diğer benzimidazol türevi maddelerin antibakteriyal özellikleri incelendiğinde; E. coli'e 14 ve 15 no'lu maddelerin, S. aureus'a 2, 14 ve 15 no'lu maddelerin, B. subtilis'e 4 ve 15 no'lu maddelerin ve $P$. aeruginosa'a ise 2,3 ve 15 no'lu maddelerin etkin olduğu ve inhibisyon zonu oluşturduğu tespit edilmiştir.

\section{Tartışma}

Bu çalışmada yapısal farklılıklar içeren bir seri benzimidazol türevinin Gram + ve Gram - bakterileri içeren klinik öneme sahip bazı mikroorganizmalara karşı etkileri farklı metotlar ile detaylı olarak incelenmiştir. Seçilen benzimidazoller, farklı sayıda benzimidazol birimi içerenler, benzimidazol halkasının 1 ve 5 konumunda farklı sübstitüent içerenler, 2-fenil benzimidazol yapısının para konumunda farklı sübstitüent içerenler ve farklı hetero aromatik birimler içeren yapılar olmak üzere yapılarına göre 5 gruba ayrilabilir.

5-Cl sübstitüsyonun benzimidazole tüm mikrobiyal türlere karşı yaygın bir aktivite kazandırdığı elde ettiğimiz sonuçlarda görülmektedir. Ayrıca, 2-fenil benzimidazolün pkonumunda elektron çekici $\mathrm{Cl}$ ve $\mathrm{NO}_{2}$ içeren türevlerin, elektron verici $\mathrm{OCH}_{3}$ ve $\mathrm{CH}_{3}$ içeren türevlere göre bakteri türlerine karşı daha etkin olduğu tespit edilmiştir. Benzimidazol halkasına 2 konumunda bağlı tiyofen ve piridin gibi hetero halkalı grupların aktiviteyi arttırdığı gözlemlenmiştir. Benzimidazol halkasına 1-konumunda alkil sübstitüsyonu antibakteriyal aktiviteyi belirgin şekilde azaltmaktadır. Ayrıca, yapılarında iki adet benzimidazol çekirdeği bulunduran bisbenzimidazol türevlerinin benzimidazole göre daha etkin olduğu belirlenmiştir. Buna ilaveten bisbenzimidazollerde Gram -'lere karşı etki daha belirgindir. 
Tablo 2. Benzidazol türevlerinin (1-15) ve test antibiyotiklerinin bazı mikroorganizmalara karşı ölçülen zon çapları (mm).

\begin{tabular}{|c|c|c|c|c|c|}
\hline \multirow[b]{2}{*}{ No } & \multirow{2}{*}{$\begin{array}{c}\text { Antimikrobiyal } \\
\text { Konsantrasyon } \\
(\mu \mathrm{g} / \mathrm{ml})\end{array}$} & \multicolumn{4}{|c|}{ Mikroorganizmalar (inhibisyon zon çapları, mm) } \\
\hline & & S. aureus $^{T}$ & B. subtilis ${ }^{\mathrm{T}}$ & $\begin{array}{l}E . \\
\text { coli }^{\mathrm{T}}\end{array}$ & P. aeroginosa ${ }^{\mathrm{T}}$ \\
\hline \multirow{4}{*}{1} & 250 & - & - & - & - \\
\hline & 500 & - & - & - & - \\
\hline & 1000 & - & - & - & - \\
\hline & 250 & - & - & - & - \\
\hline \multirow[t]{3}{*}{2} & 500 & - & - & - & - \\
\hline & 1000 & $11^{*}$ & - & - & $9 * *$ \\
\hline & 250 & - & - & - & 8 \\
\hline \multirow[t]{3}{*}{3} & 500 & - & - & - & 10 \\
\hline & 1000 & - & - & - & 12 \\
\hline & 250 & - & - & - & - \\
\hline \multirow[t]{3}{*}{4} & 500 & - & $8 * *$ & - & - \\
\hline & 1000 & - & $10 * *$ & - & - \\
\hline & 250 & - & - & - & - \\
\hline \multirow[t]{3}{*}{5} & 500 & - & - & - & - \\
\hline & 1000 & - & - & - & - \\
\hline & 250 & - & - & - & - \\
\hline \multirow[t]{3}{*}{6} & 500 & - & - & - & - \\
\hline & 1000 & - & - & & - \\
\hline & 250 & 15 & 9 & - & 11 \\
\hline \multirow[t]{3}{*}{7} & 500 & 19 & 14 & - & 12 \\
\hline & 1000 & 21 & 20 & $19^{*}$ & 14 \\
\hline & 250 & - & - & - & - \\
\hline \multirow[t]{3}{*}{8} & 500 & - & - & - & - \\
\hline & 1000 & - & - & - & - \\
\hline & 250 & - & - & - & - \\
\hline \multirow[t]{3}{*}{9} & 500 & - & - & - & - \\
\hline & 1000 & - & - & - & - \\
\hline & 250 & - & - & - & - \\
\hline \multirow[t]{3}{*}{10} & 500 & - & - & - & - \\
\hline & 1000 & - & & - & - \\
\hline & 250 & - & - & - & - \\
\hline \multirow[t]{3}{*}{11} & 500 & - & - & - & - \\
\hline & 1000 & - & - & - & - \\
\hline & 250 & - & - & - & - \\
\hline \multirow[t]{3}{*}{12} & 500 & - & - & - & - \\
\hline & 1000 & - & - & - & - \\
\hline & 250 & $7 *-13.5$ & --17.5 & --10.5 & --17 \\
\hline \multirow[t]{3}{*}{13} & 500 & $8 *-11$ & $8-13.5$ & $8 *-11$ & --10 \\
\hline & 1000 & $9 *$ & - & $10^{*}$ & - \\
\hline & 250 & - & - & -- & --- \\
\hline \multirow[t]{3}{*}{14} & 500 & 8 & - & $8 *_{--}$ & --- \\
\hline & 1000 & 9 & - & $8^{*}$ & - \\
\hline & 250 & - & - & --7.5 & --- \\
\hline \multirow[t]{2}{*}{15} & 500 & 8 & 8.5 & $8-8.5$ & --8 \\
\hline & 1000 & 10 & $12 *$ & 10 & - \\
\hline OFX & 5 & 24 & 26 & 28 & 10 \\
\hline CAR & 10 & 26 & 24 & 22 & 13 \\
\hline AMP & 10 & - & - & - & - \\
\hline AK & 30 & 20 & 23 & 21 & - \\
\hline TE & 30 & 22 & 21 & 26 & 23 \\
\hline CHX & 10 & - & - & - & - \\
\hline DMSO & & - & - & - & - \\
\hline
\end{tabular}

$\mathrm{AK}=$ Amikasin; $\mathrm{AMP}=$ Ampisilin $\mathrm{CAR}=$ Karbenisilin; $\mathrm{OFX}=$ Oflaksasin; $\mathrm{TE}=$ Tetrasiklin; $\mathrm{DMSO}=$ Dimetilsülfoksit; ${ }^{\mathbf{T}}=$ Tip suş; ${ }^{*}$ Bulanık zon; ** Yüksek oranda bulanık zon. 
$\mathrm{Bu}$ durum moleküldeki hacimsel büyümenin ve/veya biyolojik akltif benzimidazol sayısındaki artışın Gram - bakterilere etkiyi arttırdığı sonucuna götürür. Bütün bileşiklerin az yada çok etkinlik biyolojik aktiviteye sahip olması bu bileşiklerdeki aktiviteden sorumlu yapının benzimidazol halkası olduğunun kanıtıdır.

Birçok çalışmada, benzimidazol türevi bileşiklerin dikkate değer aktivitesinin antimikrobiyal aktivitede önemli rol oynayan benzimidazol halkasından kaynaklandığ belirtilmiştir [18-19]. Benzimidazol türevlerinin farklı organizmalara karşı etkilerindeki çeşitlilik mikrobiyal hücrelerin yarı geçirgenlik derecesi ve/veya mikrobiyal hücrelerin ribozomlarındaki farklılıklara bağlı olduğu literatürde de ifade edilmiştir [17].

Literatürde benzimidazollerle ilgili kantitatif yapı aktivite ilişkisi QSAR hesaplamaları çalışmalarından elde edilen sonuçlar bu çalışmada elde edilen sonuçlarla birçok yönden uyum göstermektedir. Bir seri benzimidazol ile ilgili bir QSAR çalışmasında benzimidazole 2 konumunda bağlı elektronegatif gruplar içeren halkaların aktiviteyi artırdığı buna karşın 1 konumundaki hacimli grup sübstitüsyonunun ise aktiviteyi azalttığı tespit edilmiştir. Ayrıca molekül yapılarında elektronegatif gruplar içermekle birlikte daha küçük hacimli gruplar bulunduran benzimidazollerin daha iyi etkinlik gösterdiği ve H-bağı kabul edebilme ve aromatik yapı bulundurmanın farmakofor özellikleri artırdığı bildirilmiştir [20]. Bir başka SAR çalışmasında sübstitüe benzimidazollerdeki elektron çekici grupların antimikrobiyal aktiviteyi artırdığı fakat bunun yanında molekülün geneline ait elektronik parametreler, dipol moment $\mu$, lipofilik parametre gibi özelliklerin de önemli olduğu belirtilmiştir [21]. Aynı çalışmada bir seri 2-substitüe phenyl-1Hbenzimidazollerin yapı reaktivite ilişkileri çalışılmış ve 2 konumundaki aril halkasında bulunan elektron çekici $\mathrm{NO}_{2}$ ve $\mathrm{Cl}$ gruplarının antimikrobiyal aktiviteyi artırdığ fakat $\mathrm{Cl}$ grubunun antibakteriyel, $\mathrm{NO}_{2}$ grubunun ise antifungal etkisinin daha belirgin olduğu belirtilmiştir [21].

Benzimidazol halkasının 1- konumundaki $\mathrm{CH}_{3}$ sübstitüsyonunun antimikrobiyal aktiviyi düşürdügü görülmektedir. Bazı bileşiklerdeki yetersiz inhibüsyon veya düşük aktivitenin sebebi bu maddelerin mikroorganizmaların metabolizması için gerekli olan metallerle şelat oluşturma yetenekleri ve/veya hücrenin aktif merkeziyle hidrojen bağ oluşturma yeteneklerinden kaynaklanabileceği düşünülmektedir. Gerçekte, moleküllerin su ile güçlü moleküller arası H-bağları yapması ve sudaki mikroorganizmanın gelişimini inhibe edememesi veya etkili bir şekilde bloklayamamasına sebep olduğu bildirilmiş̦tir [22]. Ayrıca düşük aktivitenin sebebi, moleküllerin düşük lipofilik özellikleri ve böylece lipit membrandan nüfüzlarının zorlaşması ile inhibisyonun engellenmesi şeklinde de açıklanmıştır [17]. Daha önce belirtildiği gibi benzimidazole 1 konumunda hacimli grup sübstitüsyonunun aktiviteyi azalttığı başka çalışmalarda da tespit edilmiştir [20].

\section{Kaynaklar}

[1] Darcan, C., Kaygusuz, Ö. ve Korkmaz, T., Antimicrobial effectiveness of $\left[\mathrm{Cu}\left(\right.\right.$ pzdc) $\left.(\text { phen })_{2}\right] \cdot 5.5 \mathrm{H}_{2} \mathrm{O}$ complex on some microorganisms, Journal of Pure and Applied Microbiology, 7, 4, 2747-2756, (2013).

[2] Kaye, K.S., Engemann, J.J., Fraimow, H.S. ve Abrutyn, E, Pathogens resistant to antimicrobial agents: epidemiology, molecular mechanisms, and clinical 
management, Infectious Disease Clinics of North America, 18, 467-11, (2004).

[3] Kumar, D., Jacob, M.R., Reynolds, M.B. ve Kerwin, S.M., Synthesis and evaluation of anticancer benzoxazoles and benzimidazoles related to UK-1, Bioorganic\&Medcinal Chemistry, 10, 12, 3997-4004, (2002).

[4] El Rashedy, A. A. ve Aboul-Enein, H. Y, Benzimidazole derivates as potential chemotherapeutic agents, Current Drug Therapy, 8, 1-14, (2013).

[5] Aboul-Enein, H.Y. ve El Rashedy, A.A., Benzimidazole Derivatives as Antidiabetic Agents, Medicinal chemistry, 5, 7, 318-325, (2015).

[6] Bansal, Y. ve Silakari, O., The therapeutic journey of benzimidazoles: A review, Bioorganic\& Medicinal Chemistry, 20, 21, 6208-36, (2012) .

[7] Salahuddin, Shaharyar, M. ve Mazumder, A., Benzimidazoles: A biologically active compounds, Arabian Journal of Chemistry, 10, 157-173, (2017).

[8] Sharma, P., Rane, N. ve Gurram, V.K., Synthesis and QSAR studies of pyrimido [4, 5-d] pyrimidine- 2, 5-dione derivatives as potential antimicrobial agents. Bioorganic \& Medicinal Chemistry Letters, 14, 4185-4190, (2004).

[9] Sharma, S., Gangal, S. ve Rauf, A., Convenient one-pot synthesis of novel 2substituted benzimidazoles, tetrahydrobenzimidazoles and imidazoles and evaluation of their in vitro antibacterial and antifungal activities, European Journal of Medicinal Chemistry, 44, 1751-1757, (2009).

[10] Eren, B. ve Bekdemir, Y., Simple, mild and highly efficient synthesis of 2substituted benzimidazoles and bisbenzimidazoles, Quimica Nova, 37, 4, 643647, (2014).

[11] Eren, B. ve Unal, A., Molecular structure and spectroscopic analysis of 1,4Bis(1-methyl-2-benzimidazolyl)benzene; XRD, FT-IR, dispersive-Raman, NMR and DFT studies, Spectrochimica Acta Part A, 103, 222-231, (2013).

[12] NCCLS Standarts. Clinical and Laboratory Standards Institute, Methods for dilution antimicrobial susceptibility tests for bacteria that grow aerobically; approved standard, 7th edition, CLSI document M7-A7, Clinical Laboratory Standards Institute, Wayne, PA, (2007).

[13] Wiegand, I., Hilpert, K. ve Hancock, R. E. W., Agar and broth dilution methods to determine the minimal inhibitory concentration (MIC) of antimicrobial substances. Nature Protocols, 3, 163-175 (2008).

[14] Sarker, S. D., Nahar, L. ve Kumarasamy, Y., Microtitre platebased antibacterial assay incorporating resazurin as an indicator of cell growth, and its application in the in vitro antibacterial screening of phytochemicals, Methods, 42, 321-324 (2007).

[15] Isik, K. ve Özdemir-Kocak, F., Antimicrobial activity screening of some sulfonamide derivatives on some Nocardia species and isolates, Microbiological Research, 164, 49-58 (2009).

[16] Gülay, Z., Antibiyotik duyarlılık testlerinin yorumu, Toraks Dergisi, 3,1, 75-88, (2002).

[17] Abdel Ghani, N.T. ve Mansour, A. M., Novel Pd(II) and Pt(II) complexes of N,N-donor benzimidazole ligand: Synthesis, spectral, electrochemical, DFT studies and evaluation of biological activity, Inorganica Chimica Acta, 373, 249-258, (2011).

[18] Unal, A. ve Eren, B., FT-IR, dispersive Raman, NMR, DFT and antimicrobial activity studies on 2-(Thiophen-2-yl)-1H-benzo[d]imidazole, Spectrochimica Acta Part A, 114, 129-136, (2013). 
[19] Kenchappa, R., Bodke, Y.D., Telkar, S. ve M. Aruna, S., Antifungal and anthelmintic activity of novel benzofuran derivatives containing thiazolo benzimidazole nucleus: an in vitro evaluation, Journal of Chemical Biology, 10, 11-23, (2017).

[20] Sharma , M. C., Structural insight for (6-oxo-3-pyridazinyl)-benzimidazoles derivatives as angiotensin II receptor antagonists: QSAR, pharmacophore identification and kNNMFA approach, Journal of Saudi Chemical Society, 19,3, 265-273, (2012).

[21] Sharma, D., Narasimhan, B., Kumar, P. ve Jalbout, A., Synthesis and QSAR evaluation of 2-(substituted phenyl)-1Hbenzimidazoles and [2-(substituted phenyl)-benzimidazol-1-yl]-pyridin-3-yl-methanones, European Journal of Medicinal Chemistry, 44, 1119-1127, (2009).

[22] Abdel Ghani, N.T. ve Mansour, A. M., Novel Ni(II) and Zn(II) complexes coordinated by 2-arylaminomethyl-1Hbenzimidazole: Molecular structures, spectral, DFT studies and evaluation of biological activity, Inorganica Chimica Acta, 104, 134-142, (2013). 